\title{
17. MAGNETOSTRATIGRAPHY OF EQUATORIAL PACIFIC SITE 503 HYDRAULIC PISTON CORES1
}

\author{
Dennis V. Kent and Dann J. Spariosu, Lamont-Doherty Geological Observatory and \\ Department of Geological Sciences, Columbia University, Palisades, New York
}

\section{INTRODUCTION}

The paleomagnetic measurement procedure at Site 503 was similar to that described for Site 502 (See preceding chapter). Each core section was measured with the longcore spinner magnetometer at 10 -cm intervals. In addition, one or more discrete samples were taken from each core section for measurement of the total magnetic vector and its stability against progressive AF demagnetization. There were noteworthy differences in conditions at Site 503, however, that affected the quality and interpretation of the magnetic data and require comment.

The most serious problem we encountered was the presence of rust scale from the drill string. Although the dark flecks typically were concentrated near the top of every recovered sediment core, they also smeared down a meter or more between the core liner and sediment, even when the sediment showed no indication of drilling disturbance. Individual rust scales proved to be highly magnetic-presumably because they incorporate small pieces of unoxidized metal. The anomalously high remanent intensities, several orders of magnitude above the uncontaminated sediment values, and scattered remanent directions observed in long-core magnetic measurements on many cores from Site 503 could be attributed to the presence of rust scale.

The presence of rust scale was a serious problem in obtaining meaningful long-core spinner magnetometer measurements on cores from Hole 503A and somewhat less so in cores from Hole 503B. The problem was very minor at Site 502, apparently because almost the same length of drill string had been used on the previous leg so that most of the rust scale had already scraped off during coring. Site 503 was located in deeper water than Site 502, and the additional drill pipe required had not been used for several months and simply rusted longer in the ocean spray.

Consequently, long-core magnetic data from at least the topmost 1.5 meters section of most cores at Site 503 was of little value for magnetostratigraphic interpretations. Since the rust contamination did not affect the interior parts of undisturbed sections of the sediment, it was possible in part to complement the reliable longcore magnetic data from lower parts of each core with discrete sample measurements from the upper section of each core. This technique is illustrated in Figure 1.

\footnotetext{
${ }^{1}$ Prell, W. L., Gardner, J. V., et al., Init. Repts. DSDP, 68: Washington (U.S. Govt. Printing Office).
}

Another problem was that we had to rely heavily on core to core orientation in order to interpret the magnetization polarities. Site 503 is situated at only $4^{\circ} \mathrm{N}$ latitude, so that the dipole inclinations should average less than $10^{\circ}$ positive values for normal polarity and $10^{\circ}$ negative for reversed polarity. In general, magnetization polarities are difficult to resolve with any degree of reliability on the basis of such low inclinations, considering that a comparable magnitude of dispersion is expected from secular variation, unstable magnetization components, and various sampling and measurement errors. Although several modifications to the coring device between Sites 502 and 503 helped to improve the reliability of core to core orientation, there is room for a great deal of improvement to make working in equatorial latitudes fruitful.

\section{MAGNETIC PROPERTIES}

The remanent intensities of the sediments at Site 503 are about a factor of five less than at Site 502, about the same as the difference reported in conventional pistoncored sediments from the Caribbean and equatorial $\mathrm{Pa}$ cific oceans. Incidently, the lower remanent intensities at Site 503 probably served to accentuate the contribution of rust contamination to the long-core magnetic measurements at Site 503.

The behavior of the NRM of discrete samples during progressive AF demagnetization is illustrated in Figures 2 and 3 . We sometimes observe a large increase in remanent intensity in the initial stages of demagnetization that may reflect the progressive removal of a normal overprint on a stable reversed direction of magnetization. Nevertheless, because there is little change in the remanent directions of most samples with demagnetization, the NRM declination measurements made with the long-core spinner can be reasonably interpreted as a measure of the characteristic magnetization of the sediment. The degree to which this assumption holds true has been tested within each section by comparing magnetically cleaned discrete sample measurements with the long-core spinner results.

\section{PRESENTATION OF RESULTS}

We used similar analytical and interpretative techniques to determine the magnetostratigraphic sequence of normal and reversed polarities described for Site 502 . Although the sample inclinations are of little utility in determining polarity at Site 503 , the improved core to core orientation was of some value in extending polarity interpretations over parts of the section. We again con- 


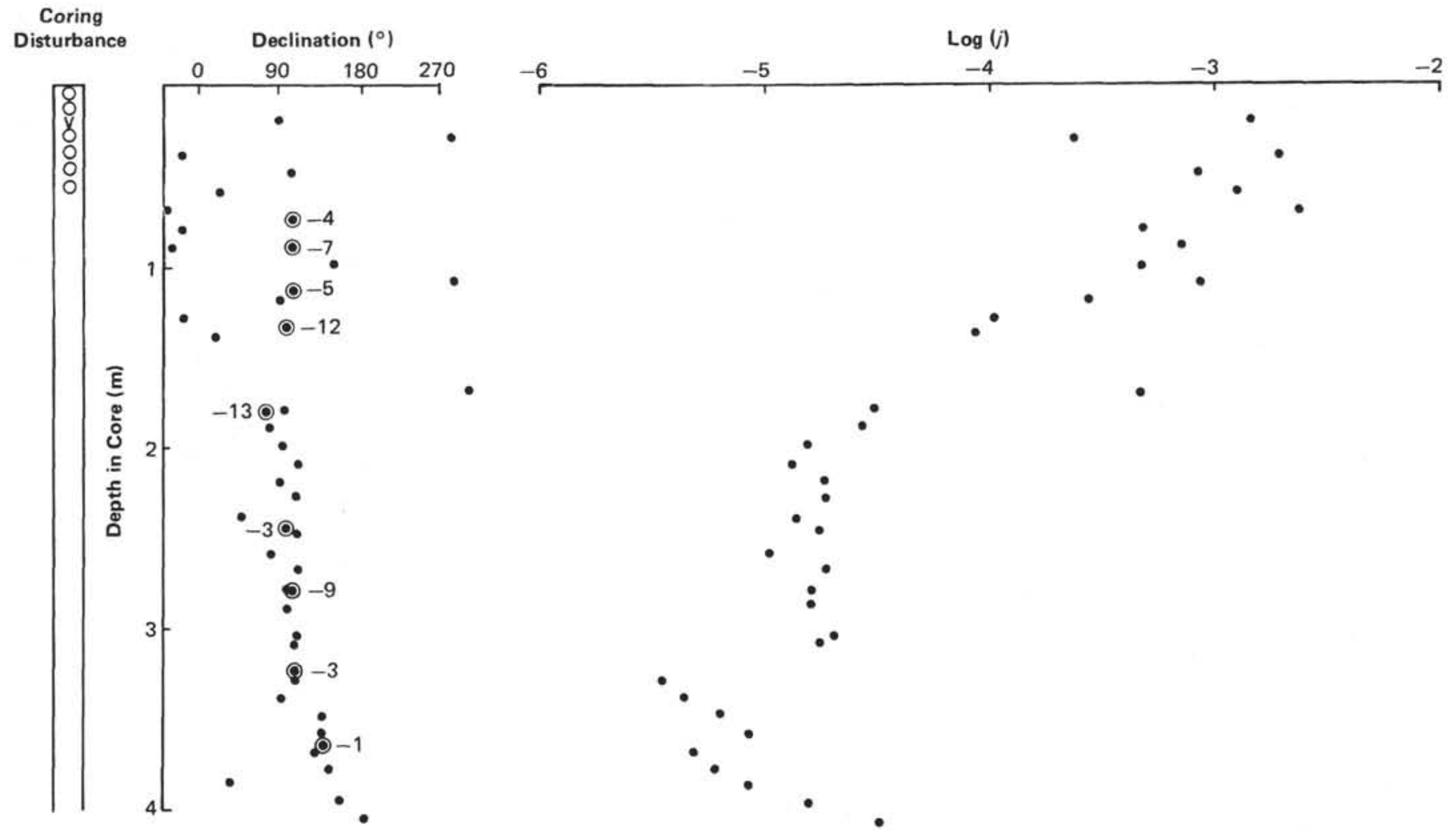

Figure 1. A typical example of the effect of rust on long-core spinner measurements (Core 503A-11). Declinations (left) show large scatter down to 1.7 meters depth. Corresponding intensities (right) are two orders of magnitude greater than sediment NRM intensities. Samples from core interior (bull's-eyes) show no rust contamination. Higher intensities and curve in declination trend near the bottom are the results of rough core handling.

centrated on the Plio-Pleistocene part of the section (approximately the upper $130 \mathrm{~m}$ ). The sediment magnetism below this level, which is near the Miocene/Pliocene boundary, becomes very weak and the internal consistencies of direction even within uncontaminated portions of the cores is poor. Interestingly, this deterioration in the quality of the paleomagnetic data occurs at about the same stratigraphic level as at Site 502. There was less undisturbed core recovery and fewer holes at Site 503 than at Site 502, which combined with the problem of rust contamination to limit magnetostratigraphic interpretation at Site 503.

The level of magnetization reversals within cores at Holes 503A and 503B and their suggested correlation to the established geomagnetic chrons are given in Table 1. The long-core and sample declination data are plotted for the cores in Holes 503A and 503B in Figures 4, 5, and 6 . We deleted long-core magnetic measurements which gave anomalously high intensities -10 or more times greater than typical sediment values-since these are probably due to rust contamination. Although the deleted measurements usually occurred at the top of most cores, high intensity values occur sporadically throughout most cores and contribute to the noise in the data.

At this stage of investigation the resulting magnetostratigraphic record can be considered at best fragmentary. Because of a lack of undisturbed core recovery and serious rust contamination, only 4 of the expected 19 polarity transitions in the Plio-Pleistocene are recorded within cores at Hole 503A. The record in Hole 503B is somewhat better: 7 polarity transitions are preserved. Taken together, Holes 503A and 503B provide fewer than half (9) of the expected polarity transitions in this time interval, and thus far the magnetostratigraphy below approximately 90 meters has not been resolved. This is in marked contrast to Site 502, where, because of a greater amount of undisturbed core recovery, minor rust contamination, and the drilling of two additional holes, a complete magnetostratigraphic sequence for the Plio-Pleistocene was obtained. Additional polarity transitions may yet be detected at Site 503 with close interval discrete sampling, particularly above 90 meters in the section where Holes 503A and 503B overlap. However, the overall poor undisturbed core recovery deeper in the section at Hole 503A presents an intrinsic ultimate limit to defining very many additional magnetozones.

\section{SEDIMENTATION RATES}

The sub-bottom depths to magnetozones we identified at Site 503 are plotted with respect to the geomagnetic polarity time scale in Figure 7. Only two polarity transitions, correlated to the Matuyama/Gauss boundary and the top of the Cochiti (Table 1), have been identified in both holes; the remaining polarity transitions occur either in Hole 503A or 503B but not both. The sub-bottom depths to the two correlative polarity transitions are apparently a little over 1 meter deeper in Hole 503B than in 503A. We arbitrarily assume the Hole 503B core 


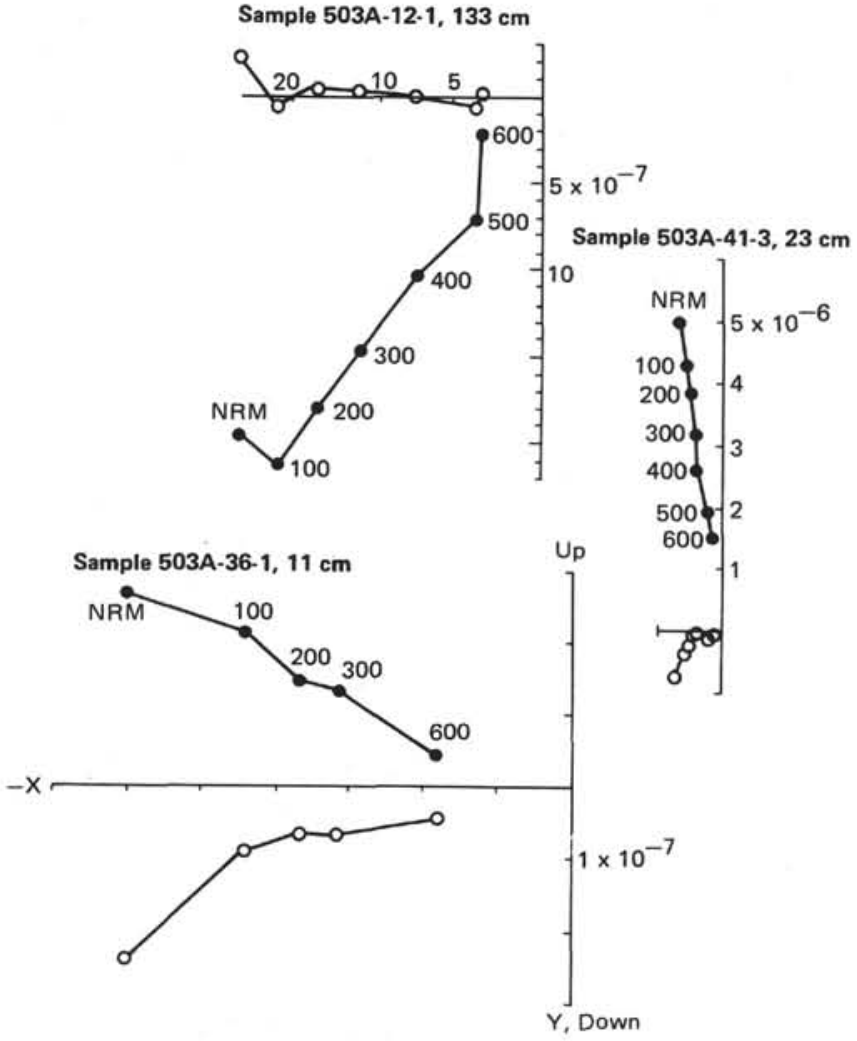

Figure 2. Results of prog̉ressive alternating field demagnetization of Site 503 samples. Open circles are projections on the X, vertical plane, closed circles projections on the horizontal plane. Demagnetization levels are in oersteds; axes units, in gauss. Note: Relative $\mathrm{X}$ and $\mathrm{Y}$ values have no directional significance. depths are correct and adjust the sub-bottom depths to polarity transitions in Hole 503A.

The average sedimentation rate from the top of the section to the top of the Cochiti, the lowest magnetozone boundary we correlate to the timescale, is about 23 $\mathrm{m} / \mathrm{m} . \mathrm{y}$. The sedimentation rates over this time interval vary from $14.8 \mathrm{~m} / \mathrm{m} . \mathrm{y}$. in the Brunhes, $21.9 \mathrm{~m} / \mathrm{m} . \mathrm{y}$. in the Matuyama, $25.3 \mathrm{M} / \mathrm{m} . \mathrm{y}$. in the Gauss, and 37.6 $\mathrm{m} / \mathrm{m} . \mathrm{y}$. in the uppermost Gilbert. Compared to analogous time intervals at Site 502, the sedimentation rates at Site 503 tend to be somewhat lower, although a similar trend of increasing sedimentation rate with depth in section is observed, until, in the Gilbert, the rates become nearly the same at both sites.

Extrapolation of the sedimentation rate in the upper Gilbert at Site 503 provides an estimate of the level of the Miocene/Pliocene boundary ( $\simeq 5.1 \mathrm{~m} . \mathrm{y}$.) at $136 \mathrm{me}$ ters which compares favorably with the biostratigraphically determined level between Cores 503A-33 and 34 (approximately $142 \mathrm{~m}$ ). The Plio-Pleistocene section at Site 503 is thus of thickness comparable to that at Site 502, where the Miocene-Pliocene boundary occurs at a sub-bottom depth of about 145 meters.

\section{ACKNOWLEDGMENT}

We thank Barbara Keating for reviewing the manuscript.

\section{REFERENCES}

LaBrecque, J. L., Kent, D. V., and Cande, S. C., 1977. Revised magnetic polarity time scale for Late Cretaceous and Cenozoic time. Geology, 5:330-335.

Mankinen, E. A., and Dalrymple, G. B., 1979. Revised geomagnetic time scale for interval 0-5 m.y.B.P. J. Geophys. Res., 84:615-626.

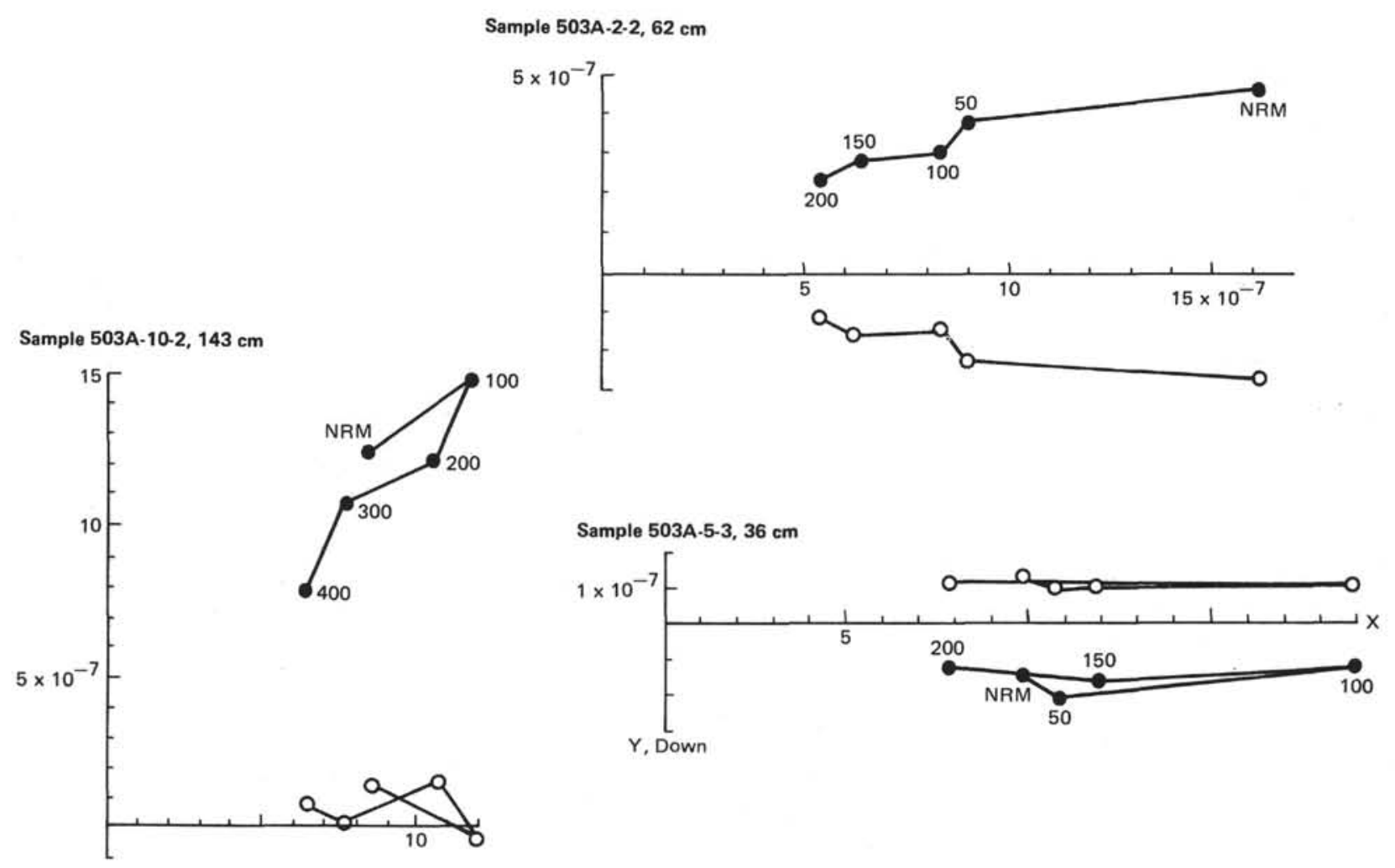

Figure 3. Progressive AF demagnetization (symbols same as in Fig. 2). Note overprint of an antiparallel component of magnetization in Samples 503A-5-3, $36 \mathrm{~cm}$ and 503A-10-2, $143 \mathrm{~cm}$. 
Table 1. Core, section, and depth in section of intervals corresponding to magnetozone boundaries interpreted in two holes at Site 503.

\begin{tabular}{|c|c|c|}
\hline & \multicolumn{2}{|c|}{$\begin{array}{c}\text { Sample } \\
\text { (interval in } \mathrm{cm} \text { ) }\end{array}$} \\
\hline & $503 \mathrm{~A}$ & $503 \mathrm{~B}$ \\
\hline $\begin{array}{l}\text { Magnetozone Boundary } \\
\text { Jaramillo }\end{array}$ & - & $3-3,60-70$ \\
\hline top & $4-2,100-120$ & - \\
\hline bottom & - & $4-2,30-40$ \\
\hline \multicolumn{3}{|l|}{ Olduvai } \\
\hline top & - & - \\
\hline bottom & $9-2,100-130^{\mathrm{a}}$ & $7-3,100-8-2,20^{\mathrm{a}}$ \\
\hline Matuyama/Gauss & $12-2,60-90$ & $12-2,60-100$ \\
\hline \multicolumn{3}{|l|}{ Kaena } \\
\hline top & $14-3,30-40^{\mathrm{a}}$ & - \\
\hline bottom & - & - \\
\hline \multicolumn{3}{|l|}{ Mammoth } \\
\hline top & - & $15-3,80-100$ \\
\hline bottom & - & $16-2,75-140$ \\
\hline Gauss/Gilbert & & $(17-3,80-100)$ \\
\hline \multicolumn{3}{|l|}{ Cochiti } \\
\hline top & $21-3,10-40^{\mathrm{a}}$ & $21-3,25-45$ \\
\hline
\end{tabular}

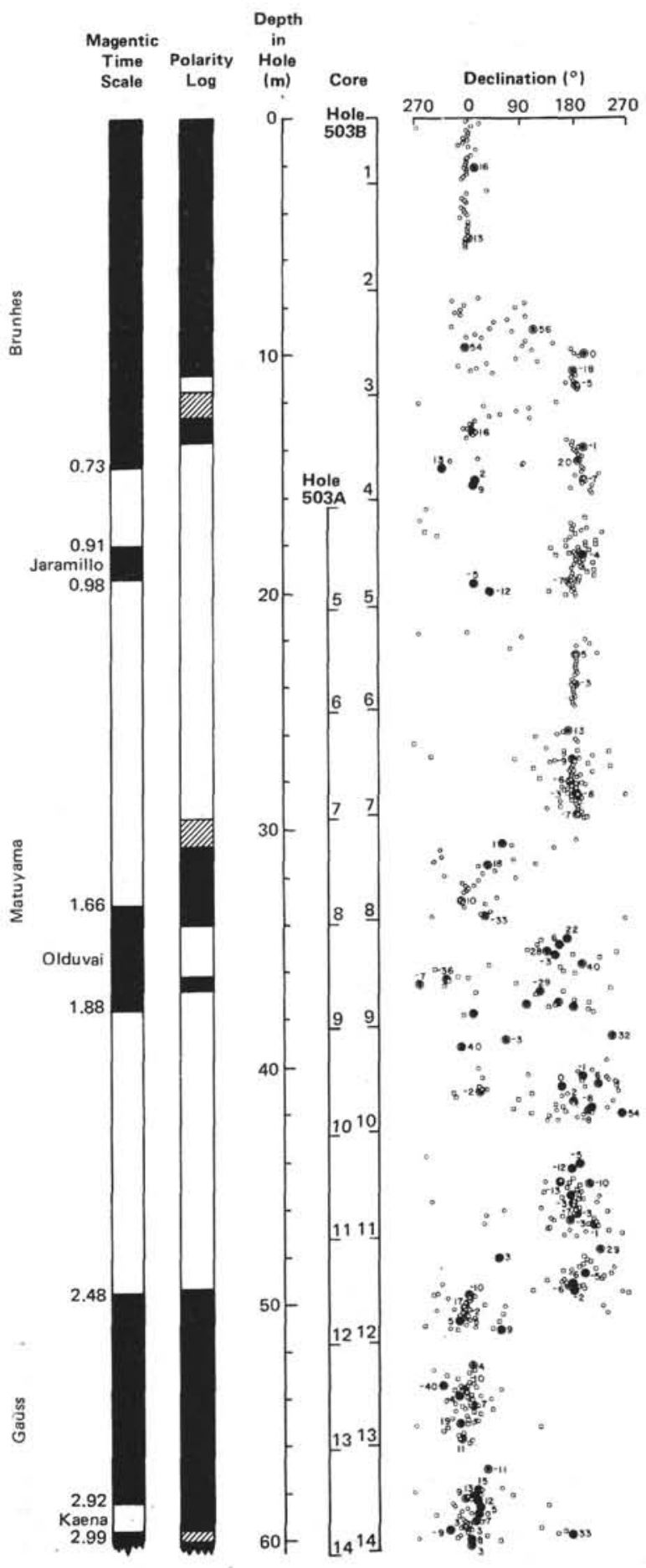

Figure 4. Composite magnetostratigraphy of the section at Site 503, 0-60 meters. Columns from left to right: (1) geomagnetic polarity time scale from LaBrecque et al. (1977) with corrected ages after Mankinen and Dalrymple (1979); (2) polarity log of interpreted magnetozones, solid (open) bar indicating normal (reversed) polarity; (3) depth in section based largely on Hole 503B; (4) cores used in assembling composite; (5) remanent declinations measured with the long-core spinner (Hole 503A: open squares, 503B: open circles). Circled solid circles are sample directions (either NRM or cleaned to 50 or $100 \mathrm{Oe}$ ); adjacent numbers are the measured inclination values for each sample. Declinations within each core have been uniformly adjusted to average $0^{\circ}$ for interpreted normal polarity and $180^{\circ}$ for reversed polarity. Magnetic measurements with anomalously high intensities due to rust contamination and from sedimentologically disturbed intervals have been omitted. 


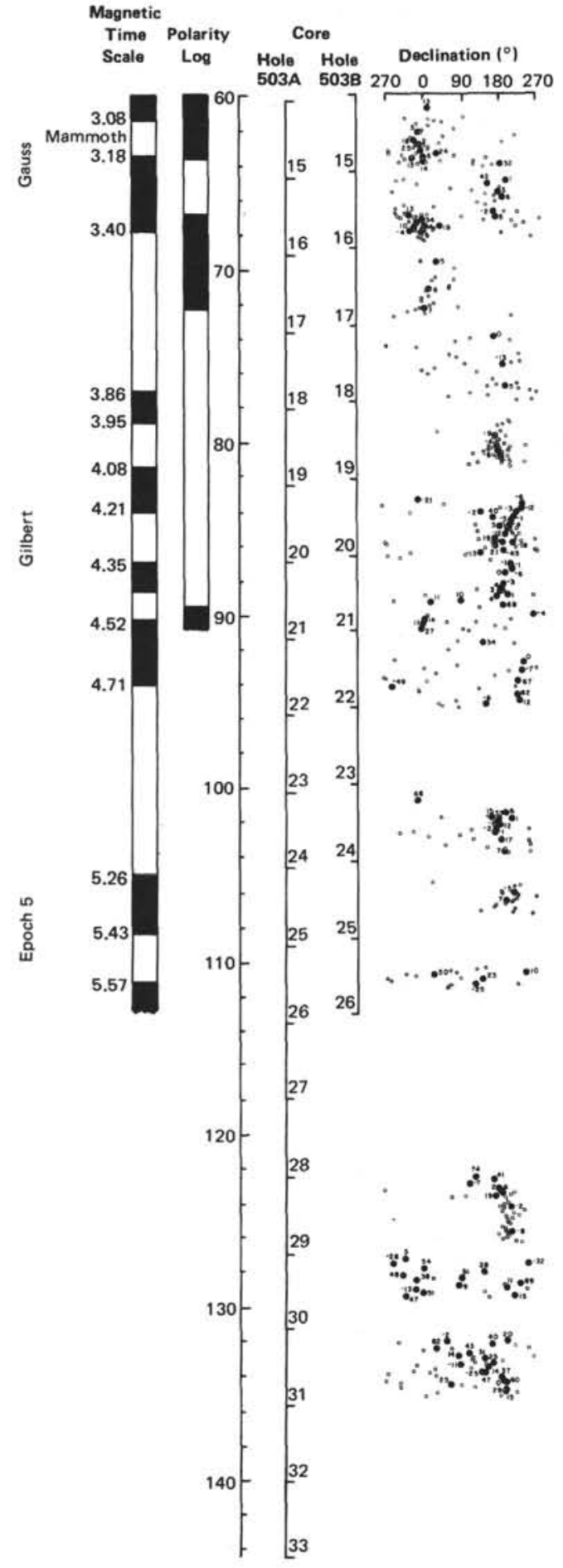

Figure 5. Composite magnetostratigraphy for Site 503, 60-144 meters (as in Fig. 4 except that no polarity interpretations and no declination adjustments have been made below $92 \mathrm{~m}$ ).

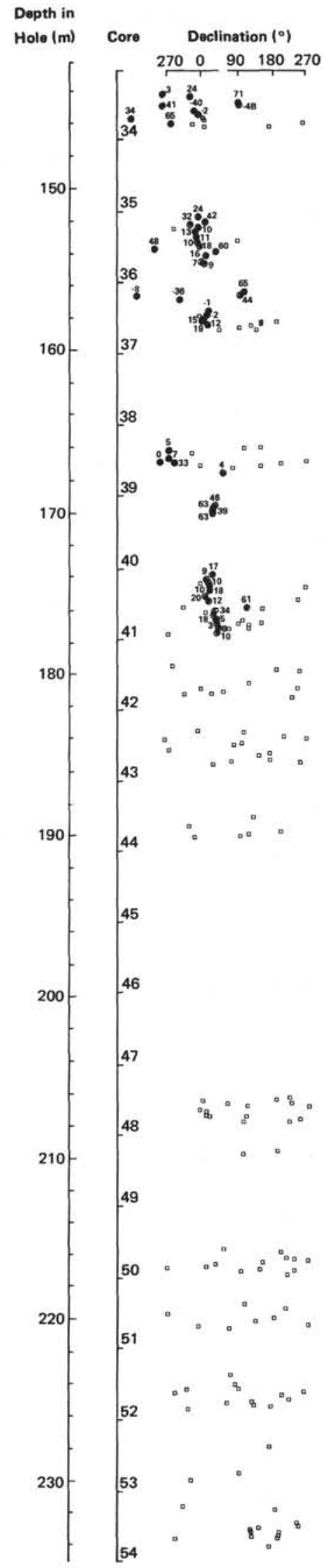

Figure 6. Paleomagnetic data for lower part of section in Hole 503A. No polarity interpretations or declination adjustments have been made. 


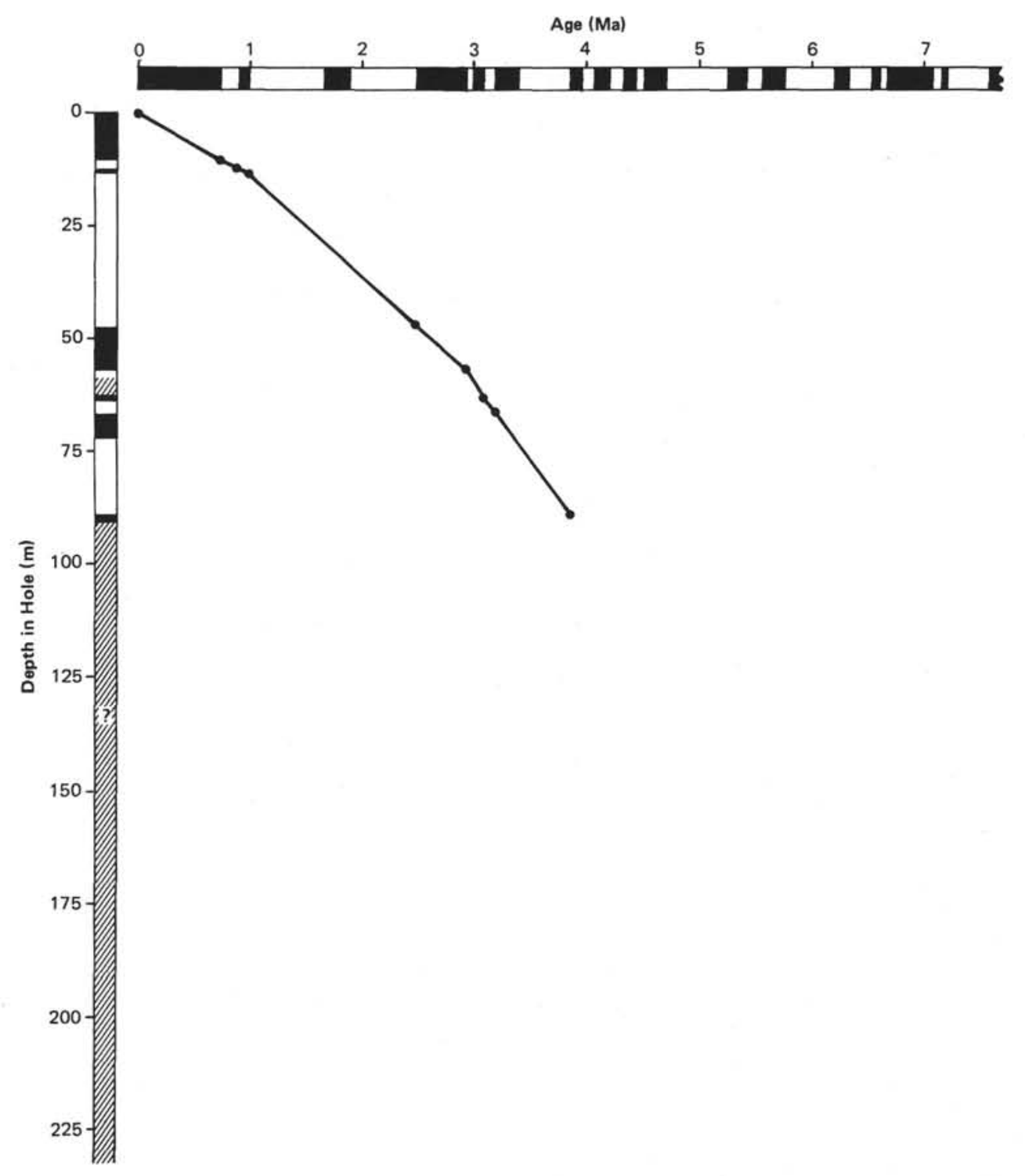

Figure 7. Sub-bottom depth to magnetozones at Site 503 plotted with respect to ages of correlative chrons according to the geomagnetic time scale of LaBrecque et al. (1977) modified after Mankinen and Dalrymple (1979). 